\title{
MODIFICATION OF VENTRICULAR GALLOP RHYTHM INDUCED BY POOLING OF BLOOD IN THE EXTREMITIES
}

\author{
BY \\ JAMES J. LEONARD, ARNOLD M. WEISSLER, AND JAMES V. WARREN \\ From the Department of Medicine, Duke University School of Medicine, Durham, North Carolina*
}

Received November 7, 1957.

Ventricular gallop is a low-pitched early diastolic sound occurring at the termination of the rapid phase of ventricular filling, it is commonly encountered clinically as a sign of incipient or actual congestive heart failure. Since this sound appears to be related to the dynamics of diastolic ventricular inflow, it was felt that additional information regarding its genesis might be obtained from a study of the effects of peripheral pooling of blood. In normal subjects tourniquet pooling of blood has been extensively studied and has been shown to produce appreciable pressure and flow alterations within the heart. The present report deals with the effects of such a procedure in 18 patients with ventricular gallop rhythm.

\section{MATERIALS AND METHODS}

Eighteen patients in hospital were studied. The majority had hypertensive cardiovascular disease or idiopathic myocardial failure. Although most had previously had evidences of cardiac failure, they were, at the time of the study, either compensated or displaying minimal evidence of failure. Only patients with gallop sounds that were readily audible and phonocardiograms free from extraneous respiratory sounds or interfering cardiac murmurs were utilized. Because the patients were studied while they were lying quietly on a flat comfortable surface, those who were dyspnœic, restless, or orthopnœic could not be satisfactorily investigated. Since the purpose of the cuffs was to trap blood in the extremities, patients with peripheral œdema were not included. If phonocardiograms or apex tracings gave evidence that the sound represented partial or complete summation with an atrial gallop sound or the præcordial atrial wave, it was discarded.

All sound tracings were taken on the logarithmic scale with the Sanborn Twinbeam photographic recording instrument at a paper speed of $75 \mathrm{~mm}$./sec. The standard $50-\mathrm{mm}$. open bell chest piece was placed on the chest wherever the sounds to be investigated were best demonstrated. This was usually at the apex. In many instances additional tracings were taken to record the linear or apex cardiogram utilizing a piezo-electric crystal microphone. These vibrations were recorded simultaneously with and from the same chest piece as the logarithmic phonocardiograms.

In order to study the effect of peripheral blood pooling, pneumatic cuffs were placed around all extremities. Care was taken to apply the cuffs as high as possible without causing discomfort. The cuffs were inflated simultaneously and rapidly to the diastolic blood pressure, or $100 \mathrm{~mm}$. of mercury in those with severe diastolic hypertension. Inflation was sustained for five minutes and the cuffs suddenly released. Following control sound tracings, recordings were made at minute intervals during the period of inflation. The period during cuff release and one minute thereafter was also recorded.

* This research was supported in part by the United States Air Force through the Air Force Office of Scientific Research of the Air Research and Development Command under contract No. AF18(600)1542, and by a research fellowship (Dr. Weissler) from the American Heart Association, and by a research grant (H-1217), and a Traineeship (Dr. Leonard) from the National Heart Institute, National Institutes of Health, Public Health Service. 


\section{RESULTS}

Control phonocardiograms showed the ventricular gallop deflections usually 2-3 cycles in duration, occurring $0 \cdot 14$ to 0.24 second after the onset of the second sound (Fig. 1). The apex cardiograms demonstrated large, steep, pointed, filling waves, the peaks of which were simultaneous with the gallop sound (Fig. 2). In many instances these waves represented the most prominent excursion of the chest wall during the cardiac cycle.

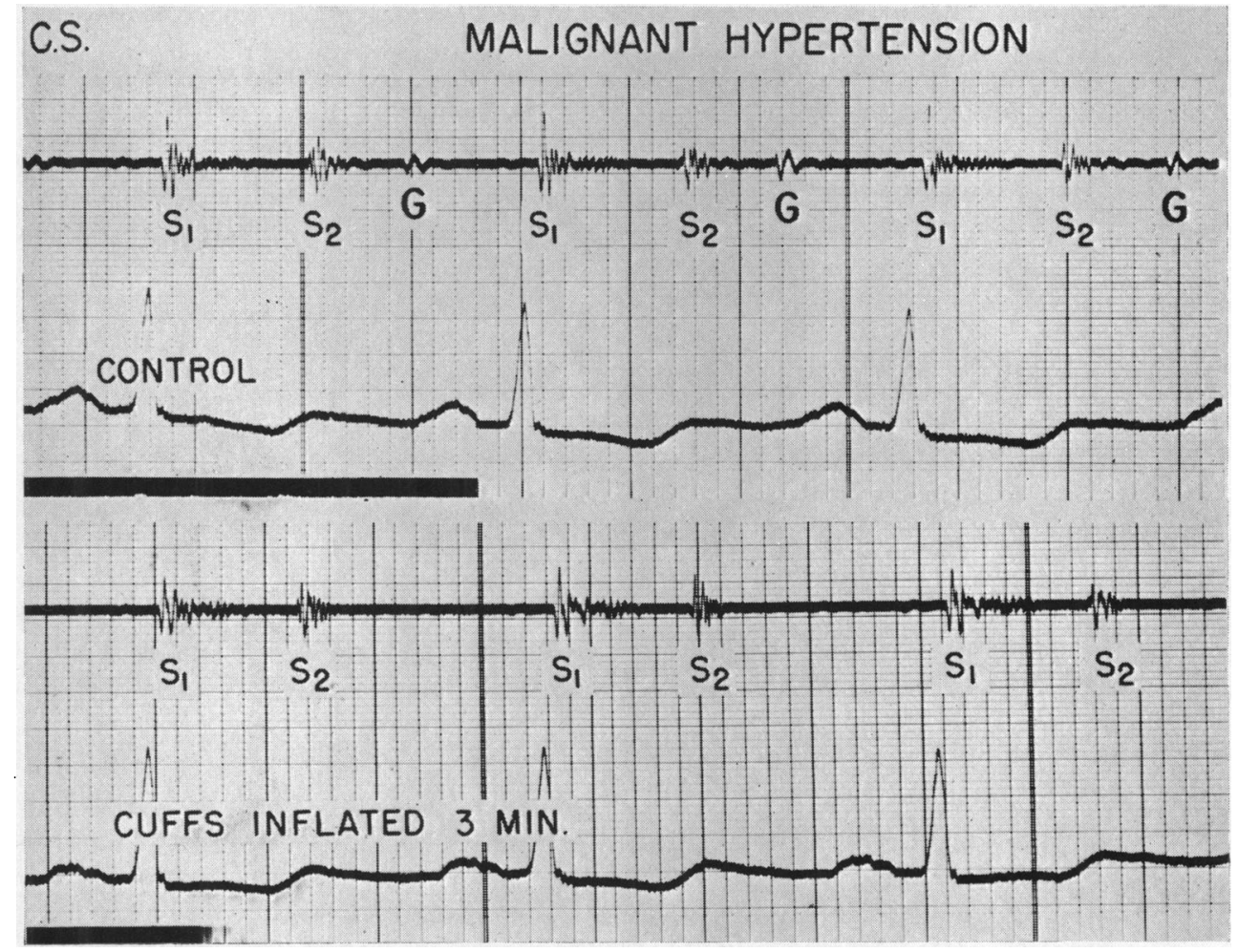

Fig. 1.-Simultaneous electrocardiograms and logarithmic phonocardiograms taken from a patient with a prominent ventricular gallop (G). The lower tracing taken three minutes after inflation of venous occlusive cuffs shows the gallop to have disappeared.

With cuff inflation in eight cases ( $44 \%$ of entire group studied) the gallop sound progressively decreased in intensity until it completely disappeared (Fig. 1). In two others (11\%) there was a striking decrease in the amplitude of the sound, but it was still visible on the tracings obtained during the fifth minute of inflation.

Accompanying these changes there was a similar and concurrent decrease in the amplitude of the apex cardiogram, the sharply spiked wave being replaced by a more gently sloped filling curve (Fig. 2). While the cuffs were inflated, no significant changes in the pulse rate or intensity of the second heart sound were noted.

The first sound increased with cuff inflation in two cases. Both were patients with severe hypertension and prominent atrial sounds in addition to the ventricular gallop. Such an increase in the first heart sound occurs frequently after blood pooling in patients with atrial gallop rhythm (Leonard et al., 1957).

A few cycles after release of cuffs the gallop sound and præcordial wave returned. The magnitude of both then frequently exceeded their initial amplitude for the next 10-20 beats before 
returning to the control level. In some instances, as the peak of apex cardiograms became steeper, it moved closer to the second heart sound (Fig. 3). The gallop sound also occurred earlier and appeared to be sharper and higher pitched.

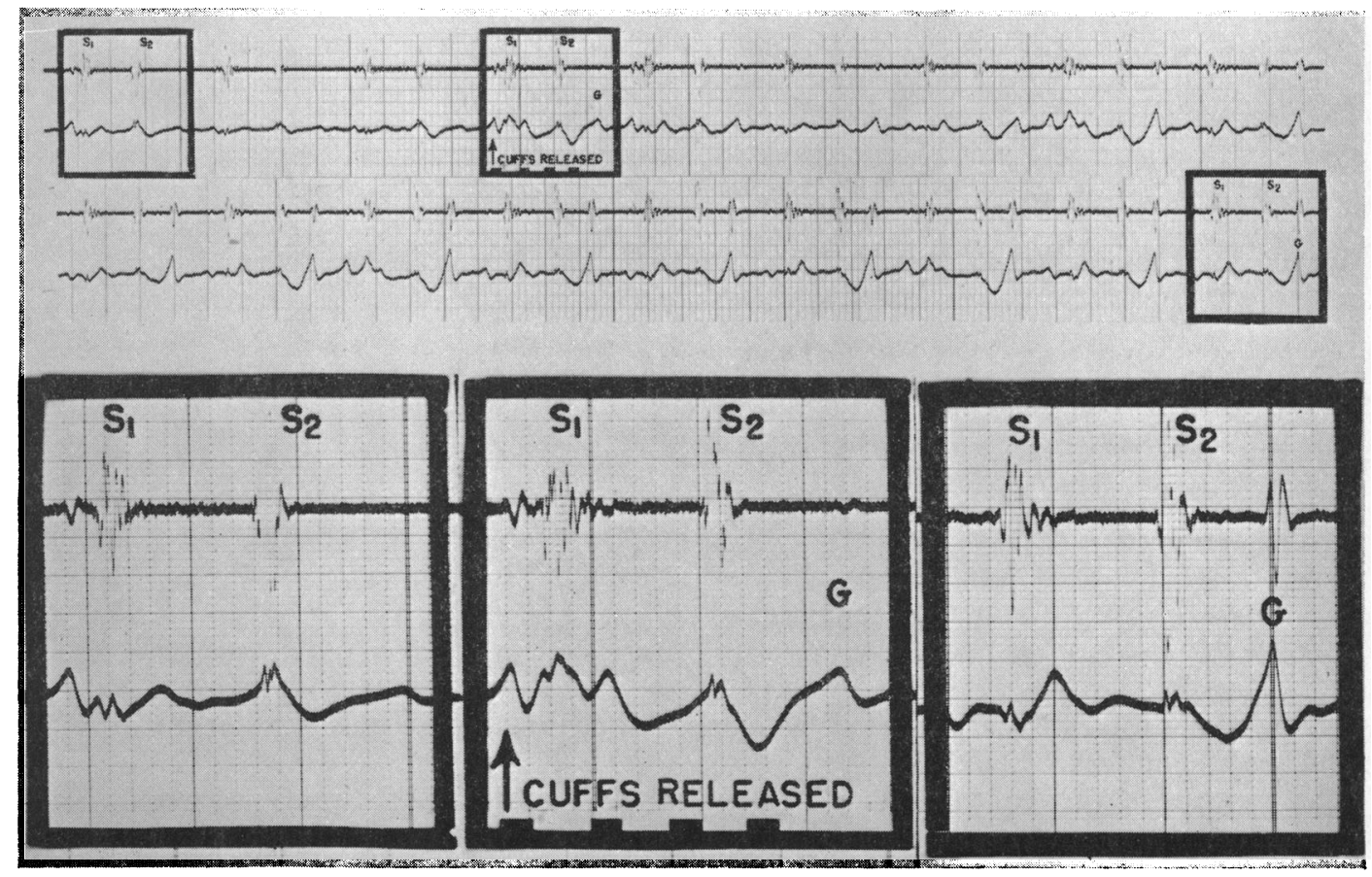

FIG. 3.-Simultaneous logarithmic phonocardiogram and apex cardiogram. Upon release of venous occlusive cuffs the diastolic filling wave of the apex cardiogram becomes larger, steeper, and its peak occurs earlier. The gallop sound (G) which has returned upon release of cuffs occurs simultaneously with the peak of this diastolic wave. As the peak of the wave becomes steeper and occurs progressively closer to the second heart sound, similar changes occur in the timing of the gallop sound. 


\section{Discussion}

The patients observed in this study have recorded diastolic sounds satisfying the criteria for a ventricular (protodiastolic, rapid ventricular filling) gallop (Wolferth and Margolies, 1933). All were patients with serious cardiovascular disease and most had evidence of congestive heart failure. From an acoustic and probably mechanical standpoint, the sound recorded is essentially the same as the physiological third heart sound (Dock et al., 1955). It differs in that it is now associated with a failing heart, the relationships to other vascular phenomena being exactly the same. It is of note that pathological gallop sounds are usually accompanied by a much more prominent apical impulse than the physiological third sound. The apex cardiogram, as well as the audible sound, is altered by blood pooling.

Tourniquets applied in the fashion used in this study pool significant amounts of blood in the extremities (Ebert and Stead, 1940). The resultant diminution of blood contained within the head and trunk is manifest by a fall in venous pressure (Warren and Stead, 1943). In addition, decreases in pressure have been observed in the chambers of the right heart and throughout the pulmonary circulation in both man (Doyle et al., 1951) and animal (Henry et al., 1956). The pressure gradients, however, remain relatively unchanged. Although observations on cardiac output have yielded somewhat varied results (McMichael and Sharpey-Schafer, 1944; Warren et al., 1945; Fitzhugh et al., 1953), it would appear most likely that there is a small decline in cardiac output. The striking change in apex impulse noted in our tracings would indicate an altered rate of ventricular filling. It has already been noted that the application of tourniquets to the extemities often results in the eradication of the physiological third heart sound (Sloan and Wishart, 1953). It is not surprising, therefore, that blood pooling has a similar effect on gallop sounds.

The exact mechanism producing the gallop sound is not understood. It has been suggested that it arises from vibrations in the pericardium, the wall of the ventricle, or from the valve leaflets themselves. A recent critical evaluation by Dock and his colleagues (1955) has led them to the conclusion that the valvular theory has more evidence in its support. On the other hand, there have been recent observations with intracardiac pressure tracings, which are interpreted as being more compatible with the wall thesis (Kuno et al., 1957). The observations recorded here are not specifically in support of any one theory. They provide further evidence that the sound is indeed causally related to the influx of blood into the ventricular cavity. In theory, the disappearance of the gallop may be due to changes in the volume elasticity characteristics of the ventricle resulting from either a fall in intracavitary pressure, slowed ventricular filling, or perhaps diminished residual blood in the ventricle.

It is of interest to note the changes in the gallop sound that occur on tourniquet release. With the first appearance of the gallop it is of low amplitude. In the ensuing beats, as ventricular flow increases, the intensity is augmented and in some cases the sound is seen to migrate closer to the second heart sound. Such alterations in amplitude and timing with changes in ventricular inflow are reminiscent of changes observed by Mounsey (1955) in the early diastolic sound of constrictive pericarditis following successful operative therapy. Available evidence indicates that this latter sound represents an altered ventricular gallop. These observations are consistent with the thesis that factors related to pressure volume characteristics of the heart are important not only in determining the presence of a gallop sound, but its timing and sound characteristics.

In the course of the observations reported here, it became apparent that a practical usefulness was evolving. In certain patients there is a difficulty on clinical grounds in differentiation between a ventricular gallop and other sounds such as a split second sound or an opening snap of mitral stenosis. It has been our experience that tourniquet application which alters the ventricular gallop sound does not effect the opening snap or the splitting of the second sound (Warren et al., 1957). The atrial (presystolic) gallop sound is also altered by the pooling of blood, but fortunately can usually be distinguished by simple auscultation. 


\section{SUMmaRY AND CONCLUSIONS}

The peripheral pooling of blood by venous occlusive tourniquets, with resultant alterations in pressure flow relationships within the heart, causes a diminution or disappearance of the ventricular gallop sound in most instances. This procedure may be useful in differentiating a ventricular gallop from an opening snap or a split second sound.

\section{REFERENCES}

Dock, W., Grandell, F., and Taubman, F. (1955). Amer. Heart J., 50, 449.

Doyle, J. T., Wilson, J. S., Estes, E. H., and Warren, J. V. (1951). 'J. clin. Invest., 30, 345.

Ebert, R. V., and Stead, E. A. (1940). J. clin. Invest., 19, 561.

Fitzhugh, F. W., McWhorter, R. L., Estes, E. H., Warren, J. V., and Merrill, A. J. (1953), J. clin. Invest., $32,1163$.

Kuo, P. T., Schnabel, T. G., Jr., Blakemore, W. S., and Whereat, A. F. (1957). J. clin. Invest., 361035.

Henry, J. R., Gauer, O. H., and Sieker, H. O. (1956). Circulation Research, 4, 91.

Leonard, J. J., Weissler, A. M., and Warren, J. V. (1957). Circulation (to be published).

McKusick, V. A. (1952). Bull. Johns Hopkins Hosp., 90, 27.

McMichael, J., and Sharpey-Shafer, E. P. (1944). Brit. Heart J., 6, 33.

Mounsey, P. (1955). Brit. Heart J., 17, 143.

Sloan, A. W., and Wishart, M. (1953). Brit. Heart J., 15, 25.

Warren, J. V., Brannon, E. S., Stead, E. A., and Merrill, A. J. (1945). J. clin. Invest., $24,337$.

, Leonard, J. J., and Weissley, A. M. (1957). Ann. intern. Med. (to be published). , and Stead, E. A. (1943). Amer. J. med. Sci., 205, 501.

Wolferth, C. C., and Margolies, A. (1933). Amer. Heart J., 8, 441. 